\title{
sciendo
}

\section{REPLACEMENT OF FISH MEAL BY SOLID STATE FERMENTED LUPIN (LUPINUS ALBUS) MEAL WITH LACTOBACILLUS PLANTARUM 299V: EFFECT ON GROWTH AND IMMUNE STATUS OF JUVENILE ATLANTIC SALMON (SALMO SALAR)}

\author{
Uriel Rodríguez-Estrada ${ }^{1,2}$, Katerina González-Alfaro ${ }^{3}$, Carolina Shene ${ }^{4}$
}

\author{
${ }^{1}$ Cátedras CONACYT (National Council of Science and Technology of México Federal \\ Government), Insurgentes sur 1582, Colonia Crédito Constructor, ZIP 03940, Delegación Benito \\ Juárez, México City, México \\ ${ }^{2}$ Laboratory of Tropical Aquaculture, DACBiol (Academic Division of Biological Sciences) - UJAT \\ (Juarez Autonomous University of Tabasco), Villahermosa Cárdenas road km 0.5, ZIP: 86039, \\ Villahermosa, Tabasco, México \\ ${ }^{3}$ Department of Chemistry and Biology Sciences, Faculty of Natural Resources, \\ Catholic University of Temuco, Temuco, Chile \\ ${ }^{4}$ Department of Chemical Engineering, Faculty of Engineering and Science, \\ Scientific and Technological Bioresource Nucleus, BIOREN, de la Frontera University, Temuco, Chile \\ •Corresponding author: rodriguez_estrada_uriel@yahoo.com
}

\begin{abstract}
The aim of this study was to assess quality of solid state fermented (SSF) lupin with Lactobacillus plantarum 299v, and its effects (on growth, feed utilization, digestibility and immunity) of juvenile Atlantic salmon (Salmo salar), when used as fish meal replacer. Five experimental diets were formulated to provide $40 \%$ crude protein and $21 \%$ dietary lipid (dry matter basis) with the raw or fermented lupin meal-based protein source replacing fish meal at $15 \%$ and $30 \%$. Triplicate groups of fish (averaging $3.53 \pm \mathbf{0 . 0 5} \mathrm{g}$ ) were fed with experimental diets for 8 weeks. Fermentation process modified nutrient profile of lupin meal and enriched it with lactic, citric and acetic acids. Fish in the FL15\% group showed a higher $(\mathrm{P}<0.05)$ final body weight, weight gain, FCR, SGR, and PER compared to those of $\mathrm{C}$ group. Apparent digestibility coefficient (ADC) of protein and nitrogen-free extract showed significantly higher values in FL15\% experimental group, compared to those shown in $\mathrm{C}$ group. Fish in the $\mathrm{FL15 \%}$ group showed a higher $(\mathrm{P}<0.05)$ lysozyme activity and leucocyte respiratory burst compared to that shown by fish samples in the $\mathrm{C}$ experimental group; phagocytic activity did not record differences among experimental groups. In conclusion, replacement of fish meal by raw or fermented lupin meal did not compromise growth, apparent digestibility coefficients and immune status of juvenile Atlantic salmon and even improved fish performance when supplemented at $15 \%$.
\end{abstract}

Key words: Atlantic salmon, digestibility, growth, immunity, lupin meal 
Fish meal (FM) has been widely used for manufacturing aquafeeds because of its long-chain omega-3 fatty acids, vitamins and minerals, and balanced amino acids essential for cultured fish growth (Al-Thobaiti et al., 2017; Tacon and Metian, 2015; Zhang et al., 2018). However, decreases in fisheries stocks and high price of fish meal have made it hard to meet the aquaculture consumption demands of this industry. In consequence, a global priority for finding alternative protein sources to replace fish meal in aquafeeds is essential (Sun et al., 2015). As a response, plant protein sources to replace FM have attracted scientific and industrial attention. Lupin is a promising plant protein source due to its mass supply, price and nutrient contents (Tabrett et al., 2012). Studies have been conducted in order to determine the effects of lupin in fish (Glencross et al., 2003; Salini and Adams, 2014), observing neither no negative effects nor a decrease in growth of fish (Acar et al., 2018).

Fermentation or bioprocessing of plant proteins is an alternative for improving nutrients profile and enriching fermented substrate with a series of secondary metabolites (Ray, 2001). Solid state fermentation (SSF) is a method in which inoculation is done on a solid substrate, such as a plant meal, with microorganisms and fermented under controlled conditions of temperature, and humidity (Pandey, 2003). Many microorganisms have been used in SSF processes. Lactic acid bacteria (LAB) is one of them (Zhang et al., 2014). There are many studies demonstrating the beneficial effects of LAB in growth, digestibility and nutrient utilization (Giri et al., 2013; VanDoan et al., 2014; Yu et al., 2017) and immunity (Gao et al., 2018; Xia et al., 2018) of aquatic animals. Lactobacillus plantarum $299 \mathrm{v}$ is a LAB that has been demonstrated to produce abundant organic acids (OA) such as lactic, citric and acetic acids (Vandenberghe et al., 2018) during fermentation process. OA are short-chain fatty acids or carboxylic acids which have antimicrobial properties and the capacity to improve growth, digestibility and immunity of aquatic animals (Sarker et al., 2011; Vielma and Lall, 2006). It has been previously demonstrated that SSF processes with Lactobacillus produce organic acids blends $(\mathrm{OAB})$ which are a mixture of OA potentiating their capacity to improve fish performance ( $\mathrm{Ng}$ and $\mathrm{Koh}, 2016)$.

Fish meal replacement by SSF plant meals in fish diets has been widely studied (Sharawy et al., 2016; Sun et al., 2015). However, studies using fermented lupin meal (with L. plantarum) as replacer of fish meal in Atlantic salmon diets, are scarce. Therefore, the aim of this study was to assess quality of SSF lupin with L. plantarum $299 \mathrm{v}$, and its effects on growth, feed utilization, digestibility and immunity of juvenile Atlantic salmon (S. salar), when used as fish meal replacer.

\section{Material and methods}

\section{Preparation of fermented lupin meal}

The bacterium L. plantarum $299 \mathrm{v}$ was isolated from a commercial probiotic product. By $16 \mathrm{~S}$ rDNA sequencing, the strain was identified as L. plantarum (sequence homology 99\%). The inoculum to the SSF was prepared in sterile defatted milk $(10 \% \mathrm{p} \mathrm{w} / \mathrm{v})$ and incubated at $37^{\circ} \mathrm{C}$ for $24 \mathrm{~h}$. The meal of dehulled lupin was 
obtained from the local market. Before using the product, a thermo-sanitation process $\left(90^{\circ} \mathrm{C}, 3 \mathrm{~h}\right)$ was applied to the meal for blocking the microbial activity. After cooling down to room temperature, lupin meal was homogeneously spread in two previously sterilized steel trays $(86 \mathrm{~cm} \times 46 \mathrm{~cm} \times 2 \mathrm{~cm})$. The grown bacterial culture $(90 \mathrm{~mL})$ was mixed with a sterile water in the amount needed to achieve $60 \%$ of humidity of total substrate; the trays were covered with plastic wrap. SSF was conducted at $37^{\circ} \mathrm{C}$ until the $\mathrm{pH}$ of liquid retained by the solid $(2 \mathrm{~g}$ of moistened substrate in $15 \mathrm{~mL}$ of water) reached a value of 4 (within $48 \mathrm{~h}$ approximately). At this point, temperature of fermentation machine was elevated to $65^{\circ} \mathrm{C}$ for drying until obtaining a constant weight. During fermentation process, humidity/moisture and bacterial content (CFU) of solid substrate were monitored at 0 h, $36 \mathrm{~h}$ and after drying. Humidity was calculated using a moisture balance (A\&D Weighing, MS70, IL, USA). Counting of CFU was conducted according to method described in Panigrahi et al. (2004). Fermented lupin was minced and kept at $4^{\circ} \mathrm{C}$ until use.

\section{Content of organic acids}

The content of organic acids (lactic, citric and acetic acid) of raw and fermented lupin meal, and experimental diets was determined by high performance liquid chromatography according to methodology described in Cunha et al. (2001) with some modifications. In brief, the chromatographic separation was achieved using reversephase column C18 (ODS) (Hypersil BDS, ThermoFisher Scientific, MA, USA). The mobile phase used was a gradient of water and acetonitrile at a flow rate of $1 \mathrm{~mL} /$ min, column temperature $60^{\circ} \mathrm{C}$, injection volume $10 \mu \mathrm{L}$. The effluent was monitored using a UV detector (EM-1 Econo UV monitor, Bio-Rad, CA, USA) at $265 \mathrm{~nm}$. Identification and quantification were based on internal standard methods.

\section{Experimental diets}

Five experimental diets were formulated to be isonitrogenous ( $42 \%$ crude protein) and isolipidic (22\% crude lipid). Diets were supplemented with $1 \%$ of chromium (III) oxide (Sigma-Aldrich, Darmstadt, Germany) as marker for digestibility test. Experimental design included a basal diet (C) formulated with a high fish meal protein source and four basal diets replacing fish meal by either raw or fermented lupin: RL15\% (basal diet $+15 \%$ raw lupin), FL15\% (basal diet $+15 \%$ fermented lupin), RL30\% (basal diet $+30 \%$ raw lupin), FL30\% (basal diet $+30 \%$ fermented lupin) (Table 1).

Diets were manufactured at the Animal Feed Pilot Plant of the Aquaculture School, Catholic University of Temuco, Chile. Prior to mixing, major meal ingredients were finely ground through a $200-\mu \mathrm{m}$ mesh using an Ultra Centrifugal Mill (Restch ZM 200, Haan, Germany). Ingredients were weighed and thoroughly mixed prior to the extrusion process. Extruded feed was obtained by a cooking-extrusion process with a laboratory twin-screw extruder (Clextral BC-21; Clextral, Firminy, France) with a 3-mm diameter die. Resultant moist pellets were oven-dried at $60^{\circ} \mathrm{C}$ for approximately $15 \mathrm{~h}$. Oil was added, according to the formulation of each diet, by means of a laboratory vacuum coater (Dinnissen model VC10, Sevenum, the Netherlands). Diets were stored at $-20^{\circ} \mathrm{C}$ until use. 
Table 1. Formulation and proximal composition $\left(\mathrm{g} \mathrm{kg}^{-1} \mathrm{diet}\right)$ of experimental diets for Atlantic salmon (Salmo salar)

\begin{tabular}{|c|c|c|c|c|c|}
\hline \multirow{2}{*}{$\begin{array}{l}\text { Ingredients } \\
\left(\mathrm{g} \mathrm{kg}^{-1} \text { diet }\right)\end{array}$} & \multicolumn{5}{|c|}{ Diets } \\
\hline & $\mathrm{C}$ & RL15\% & FL15\% & RL30\% & FL30\% \\
\hline Fish meal $^{1}$ & 562 & 480 & 475 & 397 & 387 \\
\hline Lupin meal $^{2}$ & 0 & 150 & 0 & 300 & 0 \\
\hline LAB fermented lupin meal & 0 & 0 & 150 & 0 & 300 \\
\hline Starch gel $^{3}$ & 130 & 130 & 130 & 130 & 130 \\
\hline Fish oil ${ }^{4}$ & 80 & 80 & 80 & 80 & 80 \\
\hline Raps oil ${ }^{5}$ & 70 & 66 & 66 & 63 & 62 \\
\hline Vitamin premix ${ }^{6}$ & 5 & 5 & 5 & 5 & 5 \\
\hline Mineral premix ${ }^{7}$ & 15 & 15 & 15 & 15 & 15 \\
\hline Chromium III oxide $^{8}$ & 10 & 10 & 10 & 10 & 10 \\
\hline Alpha-cellulose ${ }^{9}$ & 128 & 64 & 69 & 0 & 11 \\
\hline Total & 1000 & 1000 & 1000 & 1000 & 1000 \\
\hline \multicolumn{6}{|c|}{ Proximate composition ( $\mathrm{g} \mathrm{kg}^{-1}$ diet) } \\
\hline Dry matter & 955 & 962 & 970 & 965 & 972 \\
\hline Protein & 400 & 403 & 402 & 409 & 405 \\
\hline Lipid & 211 & 207 & 208 & 204 & 210 \\
\hline Fibre & 101 & 70 & 65 & 44 & 20 \\
\hline Ash & 117 & 109 & 110 & 101 & 95 \\
\hline Nitrogen-free extract & 185 & 215 & 222 & 250 & 265 \\
\hline Gross energy (MJ kg diet) & 21 & 22 & 22 & 22 & 22 \\
\hline Chromium III oxide & 9 & 9 & 9 & 9 & 9 \\
\hline
\end{tabular}

${ }^{1}$ Supplied by Alimentos marinos (ALIMAR S.A.) Jack Mackerel meal. Super Prime (protein 68\%, lipids $9.9 \%$, ashes $14.5 \%$ ).

${ }^{2}$ Supplied by Graneles de Chile S.A. Rancagua, Chile.

${ }^{3}$ Supplied by Productos Químicos de Chile, Santiago, Chile.

${ }^{4}$ Supplied by Biomar Chile S.A., Puerto Montt, Chile.

${ }^{5}$ Supplied by Molinera Gorbea, Gorbea, Chile.

${ }^{6}$ Supplied by DSM Nutritional Products S.A., Puerto Varas, Chile. (IU/kg or g/kg of premix): vitamin A, 1.0 MIU; vitamin $\mathrm{D}_{3}, 0.5 \mathrm{MIU}$; vitamin E, $0.04 \mathrm{MIU}$; vitamin $\mathrm{K}, 3.4 \mathrm{~g}$; vitamin $\mathrm{B}_{1}, 4$ g; vitamin $\mathrm{B}_{2}, 6$ g; vitamin $\mathrm{B}_{5}, 10 \mathrm{~g}$; vitamin $\mathrm{B}_{6}, 2 \mathrm{~g}$; vitamin $\mathrm{B}_{9}, 1.6 \mathrm{~g}$; vitamin $\mathrm{B}_{12}, 0.004 \mathrm{~g}$; niacin, $40 \mathrm{~g}$; biotin, $0.1 \mathrm{~g}$; vitamin $\mathrm{C}, 100 \mathrm{~g}$; choline, $200 \mathrm{~g}$; inositol, $50 \mathrm{~g}$.

${ }^{7}$ Supplied by BioMar Chile S.A. (per g mixture: mg; Cu: 8.3 mg; Mn: 67 mg; Co: 1.7 mg; Y: 1.7; Zn: $200 \mathrm{mg}$ )

${ }^{8}$ Supplied by Sigma Aldrich Química Limitada, Santiago, Chile.

${ }^{9}$ Supplied by Sigma Aldrich Química Limitada, Santiago, Chile.

\section{Experimental fish and feeding trial}

The feeding trial was carried out at the wetlab of the aquaculture school, Catholic University of Temuco, Chile. Juvenile salmon were transported from a local fish hatchery to the experimental facilities and once there, health status of fish was checked by visual observation, according to indications proposed by Johansen et 
al. (2006). Fish were fed with a commercial diet during the two weeks of acclimation period. At the beginning of the experiment, 750 fish (averaging $3.53 \pm 0.05 \mathrm{~g}$ ) were equally distributed in 15 tanks $(60 \mathrm{~L}$, designed with a modified feces collector-Guelph system) of an open system. Average temperature was $14^{\circ} \mathrm{C} \pm 1.5$. $\mathrm{pH}$ values recorded a range between 6.8 and 7.2. Supplemental aeration was provided to maintain the dissolved oxygen near saturation $(>85 \%)$. Each tank was then randomly assigned to one of three replicates of the five dietary treatments. The photoperiod was maintained on a 12-h light: 12-h dark schedule. Fish were fed to apparent satiation two times daily (08:00 am and 04:00 pm). Feeding trial lasted 8 weeks.

\section{Growth sampling and analysis}

Before starting experimental feeding period, twenty fish (from stocking group), and at the end of trial, twelve fish per experimental group, were sampled and stored frozen $\left(-20^{\circ} \mathrm{C}\right)$ for analysis of whole body composition. Sampling was conducted at regular intervals of 0,30 and 60 days for measuring weight and total length. Overnight fasting was done before each sampling, and the following calculations were done:

FBW (final body weight); WG (weight gain = final body weight - initial body weight); FCR (feed conversion rate = dry weight of consumed diet/gained body weight); SGR (specific growth rate $=[\ln (\mathrm{FBW})-\ln (\mathrm{IBW}))] /$ Number of rearing days $) \times 100)$; thermal growth coefficient $(\mathrm{TGC}=($ Final body weight $1 / \mathrm{FBW} / 3$-initial body weight1/IBW/3)/ Sum of daily water temperature $) \times 100)$; condition factor $(\mathrm{K}=$ (weight $(\mathrm{g}) /$ longitude $3(\mathrm{~cm}))^{*} \times 100$; and PER (protein efficiency ratio $=$ Net weight gain $(\mathrm{g}) /$ administered protein $(\mathrm{g})$ ). Feed consumption (FC) was calculated on a daily basis. Mortality was monitored throughout the experimental period.

\section{Nutrient apparent digestibility}

Two weeks before the end of feeding trial, feces were obtained on a daily basis, by setting feces collectors in each experimental tank, after last daily-feeding and syphoning uneaten feed in tanks. Feces were collected for ten consecutive days until reaching $80 \mathrm{~g}$ of pooled sample for each tank. Samples were freeze-dried (lyophilizer ALPHA 1-4 LD, Christ), powdered and kept at $-20^{\circ} \mathrm{C}$ until analysis. Chromium III oxide determination of diets and feces was conducted by atomic absorption spectrophotometry (AA-6800 spectrophotometer Shimadzu, Tokyo, Japan), according to method proposed by Furukawa and Tsukahara (1996). Data obtained was used to calculate nutrient apparent digestibility coefficients: $A D C=100-(100 \times($ Feces nutrient $\% /$ Diet nutrient $\%) \times\left(\mathrm{Cr}_{2} \mathrm{O}_{3} \% \operatorname{diet} / \mathrm{Cr}_{2} \mathrm{O}_{3} \%\right.$ feces $\left.)\right)$.

\section{Proximate composition analysis}

Proximate composition and gross energy of raw/fermented lupin meals, experimental diets, whole body and feces samples were analyzed using standard methods (AOAC, 1995).

\section{Immunity sampling and analysis}

After completion of the feeding trial, fish were starved for $24 \mathrm{~h}$ and then the final sampling was carried out. Six fish per tank ( $\mathrm{n}=18$ per treatment) were anesthetized with $20 \% \mathrm{w} / \mathrm{v}$ benzocaine (BZ-20; Veterquimica SA, Santiago, Chile) and bled by 
puncturing the caudal vein with heparinized 1-mL syringes. Fresh plasma was frozen at $-80^{\circ} \mathrm{C}$ until analyzed.

Lysozyme activity was measured by turbidimetric assay (Parry et al., 1965) using a 96-well plate using a microplate reader (Elx808 Bio Tek, USA) (absorbance 520 $\mathrm{nm}$ ). Following the method proposed by Sakai et al. (1996), respiratory burst and phagocytic activity were determined using leucocytes of anterior portion of head kidney (HK). This tissue was conserved in L-15 medium (Sigma, St. Louis, MO, USA). HK was macerated with 34/51\% (resultant cellular suspension) of Percoll gradient (Pharmacia, Uppsala, Sweden). Hanks medium was used for washing isolated interphase cells. Viable phagocytic cells were quantified by trypan blue exclusion (viability $>95 \%$ ).

Leucocyte respiratory burst activity was assessed by measuring intracellular superoxide anion production (Yin et al., 2006). A 96-well plate was used to analyze reduction of nitroblue tetrazolium (NBT). After works, optical density was measured with a multicar spectrophotometer (Spectra Count, Packard, USA) at $630 \mathrm{~nm}$. A direct counting method was used for assessing phagocytic activity of leucocytes. Percentage of leucocytes with phagocytosed cells determined the level of immune stimulation of analyzed cells.

\section{Statistical analysis}

Data analysis was done using STATISTICA software (version 12.0, StatSoft, OK, USA). Effects of treatments were determined by ANOVA analysis. Obtained data was submitted to sigma-restricted parameterization and effective hypothesis decomposition methods. In order to discriminate homogeneous groups, differences between means were analyzed by Duncan's multiple range test (5\% level of significance).

\section{Results}

\section{Solid state fermentation (SSF) and organic acids (OA)}

During all SSF process, humidity and CFU were measured (Table 2). The color of raw lupin was yellow, while after the initial heat treatment, fermentation and drying processes, the color of the meal changed to a dark-yellow. Dry matter and protein showed slightly higher values in fermented lupin meal compared to the contents of the raw lupin meal. In contrast, a lower trend was exhibited by the contents of fibre, ash and nitrogen-free extract in the fermented lupin meal, compared to those values recorded in raw lupin meal. Lactic acid was not detected in raw lupin meal, however it recorded a notably high amount in the fermented lupin meal. Citric and acetic acids increased in fermented lupin meal, compared to those shown in raw lupin meal (Table 3).

Lactic, citric and acetic acids showed higher values in diets supplemented with any level of the fermented lupin meal than those shown in diets partially supplemented with any level of raw lupin meal. Lactic and citric acids were only detected in diets supplemented with fermented lupin meal. Compared to $\mathrm{C}, \mathrm{pH}$ was lower in diets supplemented with any level of fermented lupin (Table 4). 
Table 2. Humidity (\%) and cell concentration (colony forming CFU) of the fermented lupin (Lupinus albus) meal by L. plantarum $299 \mathrm{v}$ at the inoculation time $(0 \mathrm{~h})$, after $36 \mathrm{~h}$ and after drying

\begin{tabular}{lccc}
\hline & Time $(\mathrm{h})$ & Humidity $(\%)$ & CFU/g wet basis \\
\hline 0 & 70 & $7 \times 10^{3}$ \\
36 & 65 & $10 \times 10^{7}$ \\
After drying & 6.9 & $15 \times 10^{3}$ \\
\hline
\end{tabular}

Table 3. Proximal composition $\left(\mathrm{g} \mathrm{kg}^{-1}\right)$ and organic acid ( $\mathrm{mg} \mathrm{g}^{-1}$ dry matter basis) content of raw and fermented lupin (Lupinus albus) meal with Lactobacillus plantarum 299v

\begin{tabular}{l|c|c}
\hline & Raw lupin meal & Fermented lupin meal \\
\hline Proximal composition & 910 & 940 \\
Dry matter & 380 & 410 \\
Protein & 80 & 80 \\
Lipid & 30 & 20 \\
Fibre & 30 & 25 \\
Ash & 470 & 450 \\
Nitrogen-free extract & 20 & 20 \\
Gross energy (MJ/kg) & & \\
Organic acids & 0 & 62 \\
Lactic acid & 6 & 13 \\
Citric acid & 4 & 14 \\
Acetic acid & & \\
\hline
\end{tabular}

Table 4. Organic acids ( $\mathrm{g} \mathrm{kg}^{-1}$ diet) and $\mathrm{pH}$ levels of experimental diets for Atlantic salmon (Salmo salar)

\begin{tabular}{l|c|c|c|c|c}
\hline \multirow{2}{*}{ Organic acids $\left(\mathrm{g} \mathrm{kg}^{-1}\right)$ and $\mathrm{pH}$} & \multicolumn{5}{c}{ Ingredients } \\
\cline { 2 - 6 } \multicolumn{1}{c|}{ Lactic acid } & $\mathrm{C}$ & RL15\% & FL15\% & RL30\% & FL30\% \\
Citric acid & 0.00 & 0.00 & 12.89 & 0.00 & 75.55 \\
Acetic acid & 0.00 & 1.01 & 2.18 & 2.30 & 4.92 \\
$\mathrm{pH}$ & 0.00 & 2.52 & 6.08 & 4.14 & 10.44 \\
& 5.94 & 5.88 & 5.65 & 5.87 & 5.40 \\
\hline
\end{tabular}

\section{Experimental diets proximate composition}

Dry matter content of experimental diets slightly increased as either raw or fermented lupin meal supplementation level increased. Fibre and ash content of experimental diets decreased as either raw or fermented lupin meal supplementation level increased. The content of nitrogen-free extract increased as either raw or the fermented lupin meal supplementation level increased. Protein, lipid, gross energy and chromium III oxide content did not show important differences among all experimental diets (Table 5). 


\section{Whole-body proximate composition}

The whole-body proximate composition of juvenile Atlantic salmon fed the experimental diets for 8 weeks is presented in Table 5. The results showed that there were no significant differences $(\mathrm{P}>0.05)$ in whole-body composition among fish fed different diets.

Table 5. Whole-body proximate composition ( $\mathrm{g} \mathrm{kg}$ ), after an 8 -week feeding test, of juvenile Atlantic salmon (Salmo salar) fed experimental diets formulated with $15 \%$ and $30 \%$ replacement of fish meal by either raw or fermented lupin meal

\begin{tabular}{l|c|c|c|c|c}
\hline & C & RL15\% & FL15\% & RL30\% & FL30\% \\
\hline Dry matter & $250 \pm 10.84$ & $253 \pm 14.54$ & $245 \pm 16.51$ & $249 \pm 2.63$ & $247 \pm 7.54$ \\
Protein & $125 \pm 7.00$ & $128 \pm 10.74$ & $125 \pm 1.02$ & $122 \pm 3.86$ & $123 \pm 2.14$ \\
Lipid & $76 \pm 3.40$ & $76 \pm 3.59$ & $72 \pm 5.41$ & $79 \pm 1.49$ & $74 \pm 3.13$ \\
Ash & $82 \pm 4.54$ & $83 \pm 5.71$ & $80 \pm 5.96$ & $70 \pm 4.42$ & $73 \pm 3.23$ \\
\hline
\end{tabular}

\section{Growth and survival}

All experimental diets were well accepted by the fish during the 8-week experimental period. At the end of feeding trial, final body weight, weight gain, SGR and PER were significantly $(\mathrm{P}<0.05)$ higher in FL15\% group compared to $\mathrm{C}$ group. However, FCR was significantly lower $(\mathrm{P}<0.05)$ in FL15\% compared to that of C. A significantly $(\mathrm{P}<0.05)$ higher final body weight, weight gain, $\mathrm{SGR}$ and $\mathrm{PER}$ were recorded in FL15\% compared to those shown in RL15\%. FCR recorded a significantly $(\mathrm{P}<0.05)$ lower value in FL15\%, compared to that shown in RL15\% group. Final body weight, weight gain, SGR, TGC and PER were significantly $(\mathrm{P}<0.05)$ lower in FL30\% compared to those shown in RL30\%. In contrast, FCR recorded a significantly $(\mathrm{P}<0.05)$ higher value in FL30\% compared to that shown in RL30\%. SGR was significantly $(\mathrm{P}<0.05)$ lower in FL30\% compared to that shown in FL15\% (Table 6).

Table 6. Growth, feed utilization and survival, after an 8-week feeding test, of juvenile Atlantic salmon (Salmo salar) fed experimental diets formulated with $15 \%$ and $30 \%$ replacement of fish meal by either raw or fermented lupin meal

\begin{tabular}{l|c|c|c|c|c}
\hline & $\mathrm{C}$ & RL15\% & FL15\% & RL30\% & FL30\% \\
\hline Initial body weight $\left(\mathrm{g} \mathrm{fish}^{-1}\right)$ & $3.53 \pm 0.07 \mathrm{a}$ & $3.46 \pm 0.04 \mathrm{a}$ & $3.56 \pm 0.06 \mathrm{a}$ & $3.53 \pm 0.03 \mathrm{a}$ & $3.57 \pm 0.09 \mathrm{a}$ \\
Final body weight $\left(\mathrm{g} \mathrm{fish} \mathrm{f}^{-1}\right)$ & $5.30 \pm 0.20 \mathrm{ab}$ & $5.20 \pm 0.26 \mathrm{ab}$ & $6.27 \pm 0.21 \mathrm{c}$ & $5.97 \pm 0.51 \mathrm{bc}$ & $4.67 \pm 0.25 \mathrm{a}$ \\
Weight gain $\left(\mathrm{g} \mathrm{fish}^{-1}\right)$ & $1.77 \pm 0.20 \mathrm{ab}$ & $1.74 \pm 0.26 \mathrm{ab}$ & $2.71 \pm 0.25 \mathrm{c}$ & $2.43 \pm 0.50 \mathrm{bc}$ & $1.10 \pm 0.17 \mathrm{a}$ \\
Feed intake $\left(\mathrm{g} \mathrm{fish}^{-1}\right)$ & $1.10 \pm 0.10 \mathrm{ab}$ & $0.86 \pm 0.16 \mathrm{a}$ & $1.15 \pm 0.08 \mathrm{ab}$ & $1.19 \pm 0.18 \mathrm{~b}$ & $0.90 \pm 0.07 \mathrm{ab}$ \\
FCR & $1.60 \pm 0.20 \mathrm{bc}$ & $1.70 \pm 0.33 \mathrm{bc}$ & $1.04 \pm 0.09 \mathrm{a}$ & $1.34 \pm 0.15 \mathrm{ab}$ & $2.04 \pm 0.27 \mathrm{c}$ \\
SGR & $0.68 \pm 0.10 \mathrm{ab}$ & $0.68 \pm 0.08 \mathrm{~b}$ & $0.94 \pm 0.08 \mathrm{c}$ & $0.87 \pm 0.14 \mathrm{bc}$ & $0.45 \pm 0.05 \mathrm{a}$ \\
TGC & $0.26 \pm 0.00 \mathrm{ab}$ & $0.26 \pm 0.03 \mathrm{ab}$ & $0.28 \pm 0.08 \mathrm{ab}$ & $0.34 \pm 0.06 \mathrm{~b}$ & $0.17 \pm 0.02 \mathrm{a}$ \\
PER & $1.48 \pm 0.10 \mathrm{ab}$ & $1.48 \pm 0.26 \mathrm{ab}$ & $2.41 \pm 0.21 \mathrm{c}$ & $1.83 \pm 0.20 \mathrm{bc}$ & $1.23 \pm 0.15 \mathrm{a}$ \\
K factor & $1.42 \pm 0.10 \mathrm{ab}$ & $1.34 \pm 0.08 \mathrm{ab}$ & $1.60 \pm 0.18 \mathrm{~b}$ & $1.45 \pm 0.01 \mathrm{ab}$ & $1.16 \pm 0.18 \mathrm{a}$ \\
Survival & $71.3 \pm 3.06 \mathrm{a}$ & $75.33 \pm 5.03 \mathrm{a}$ & $78.67 \pm 2.31 \mathrm{a}$ & $76.00 \pm 2.00 \mathrm{a}$ & $72.67 \pm 4.20 \mathrm{a}$ \\
\hline
\end{tabular}

FCR, feed conversion ratio; SGR, specific growth rate; TGC, thermal growth coefficient; PER, protein efficiency ratio; $\mathrm{K}$, condition factor.

$\mathrm{a}, \mathrm{b}, \mathrm{c}$ - different letters in a row denote significant $(\mathrm{P}<0.05)$ differences among experimental groups. 


\section{Nutrient apparent digestibility}

$\mathrm{ADC}$ of protein and nitrogen free extract were significantly $(\mathrm{P}<0.05)$ higher in FL15\% compared to those shown in C, RL15\%, and FL30\% experimental groups (Table 7).

Table 7. Apparent digestibility coefficients (ADC), after an 8-week feeding test, of juvenile Atlantic salmon (Salmo salar) fed experimental diets formulated with $15 \%$ and $30 \%$ replacement of fish meal by either raw or fermented lupin meal

\begin{tabular}{l|c|c|c|c|c}
\hline & $\mathrm{C}$ & RL15\% & FL15\% & RL30\% & FL30\% \\
\hline Dry matter & $69.15 \pm 0.10 \mathrm{a}$ & $70.82 \pm 1.87 \mathrm{a}$ & $73.60 \pm 1.58 \mathrm{a}$ & $74.96 \pm 0.51 \mathrm{a}$ & $72.28 \pm 4.63 \mathrm{a}$ \\
Protein & $91.10 \pm 0.43 \mathrm{a}$ & $89.02 \pm 2.58 \mathrm{a}$ & $93.95 \pm 0.46 \mathrm{~b}$ & $93.70 \pm 0.25 \mathrm{ab}$ & $88.93 \pm 3.84 \mathrm{a}$ \\
Lipid & $96.90 \pm 0.30 \mathrm{ab}$ & $95.54 \pm 1.13 \mathrm{ab}$ & $98.17 \pm 0.31 \mathrm{~b}$ & $97.99 \pm 0.44 \mathrm{~b}$ & $95.46 \pm 2.99 \mathrm{ab}$ \\
Ash & $46.50 \pm 1.44 \mathrm{a}$ & $46.69 \pm 2.68 \mathrm{a}$ & $49.27 \pm 0.57 \mathrm{a}$ & $49.64 \pm 1.71 \mathrm{a}$ & $48.26 \pm 2.80 \mathrm{a}$ \\
Nitrogen-free extract & $42.56 \pm 3.15 \mathrm{a}$ & $50.12 \pm 5.51 \mathrm{~b}$ & $60.49 \pm 4.41 \mathrm{c}$ & $51.99 \pm 0.69 \mathrm{bc}$ & $46.64 \pm 0.90 \mathrm{ab}$ \\
Gross energy & $80.83 \pm 0.02 \mathrm{a}$ & $80.32 \pm 1.17 \mathrm{a}$ & $87.85 \pm 8.73 \mathrm{a}$ & $85.52 \pm 1.33 \mathrm{a}$ & $82.28 \pm 4.09 \mathrm{a}$ \\
(MJ kg diet) & & & & &
\end{tabular}

$\mathrm{a}, \mathrm{b}, \mathrm{c}-$ different letters in a row denote significant $(\mathrm{P}<0.05)$ differences among experimental groups.

\section{Immune response}

Fish fed with a diet containing a lower supplementation of fermented lupin meal $(\mathrm{FL} 15 \%)$ recorded a significantly higher $(\mathrm{P}<0.05)$ lysozyme activity compared to that shown by fish in $\mathrm{C}$ group (Figure 1). Fish fed the FL15\% diet, showed a significantly $(\mathrm{P}<0.05)$ higher leucocyte respiratory burst compared to that recorded in fish fed the $\mathrm{C}$ diet (Figure 2). Phagocytic activity did not show significant differences $(\mathrm{P}>0.05)$ among experimental groups (Figure 3 ).

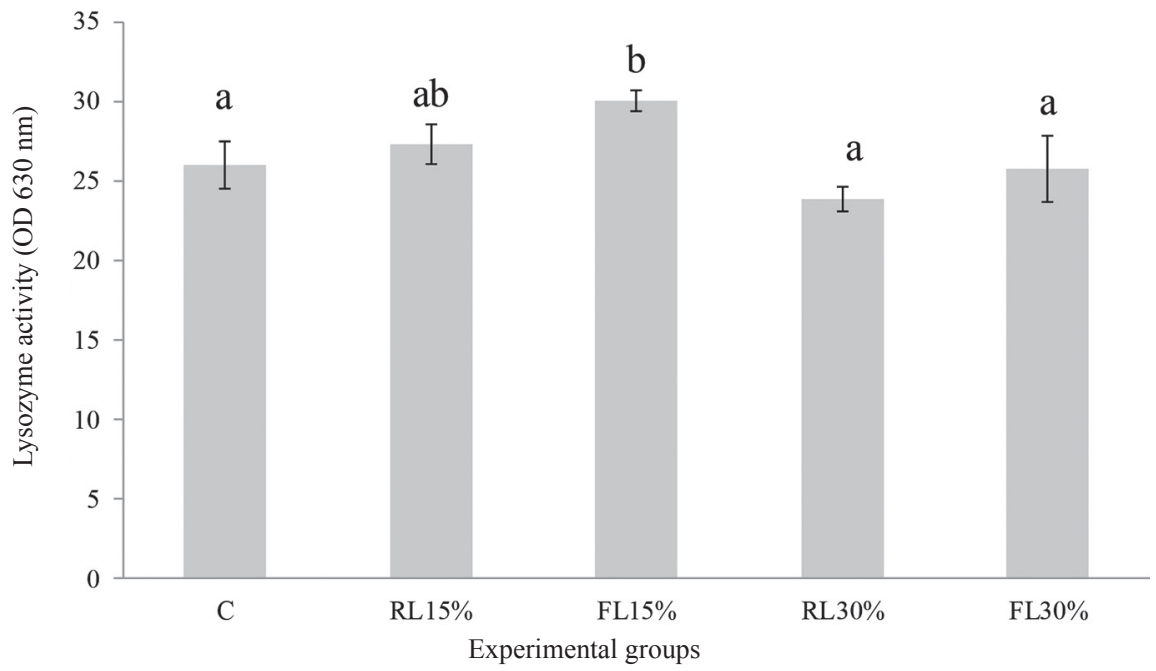

Figure 1. Lysozyme activity (mean $\pm \mathrm{SD}, \mathrm{n}=8$ ), after an 8 -week feeding test, of juvenile Atlantic salmon (Salmo salar) fed experimental diets formulated with $15 \%$ and $30 \%$ replacement of fish meal by either raw or fermented lupin meal 


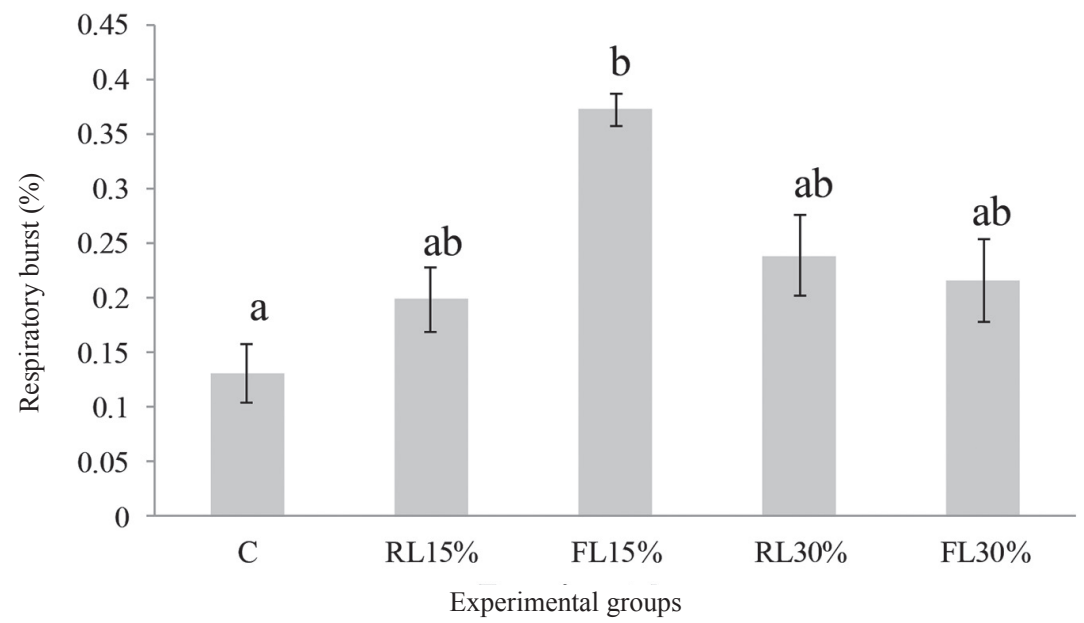

Figure 2. Respiratory burst (mean $\pm \mathrm{SD}, \mathrm{n}=8$ ), after an 8-week feeding test, of juvenile Atlantic salmon (Salmo salar) fed experimental diets formulated with 15\% and 30\% replacement of fish meal by either raw or fermented lupin meal

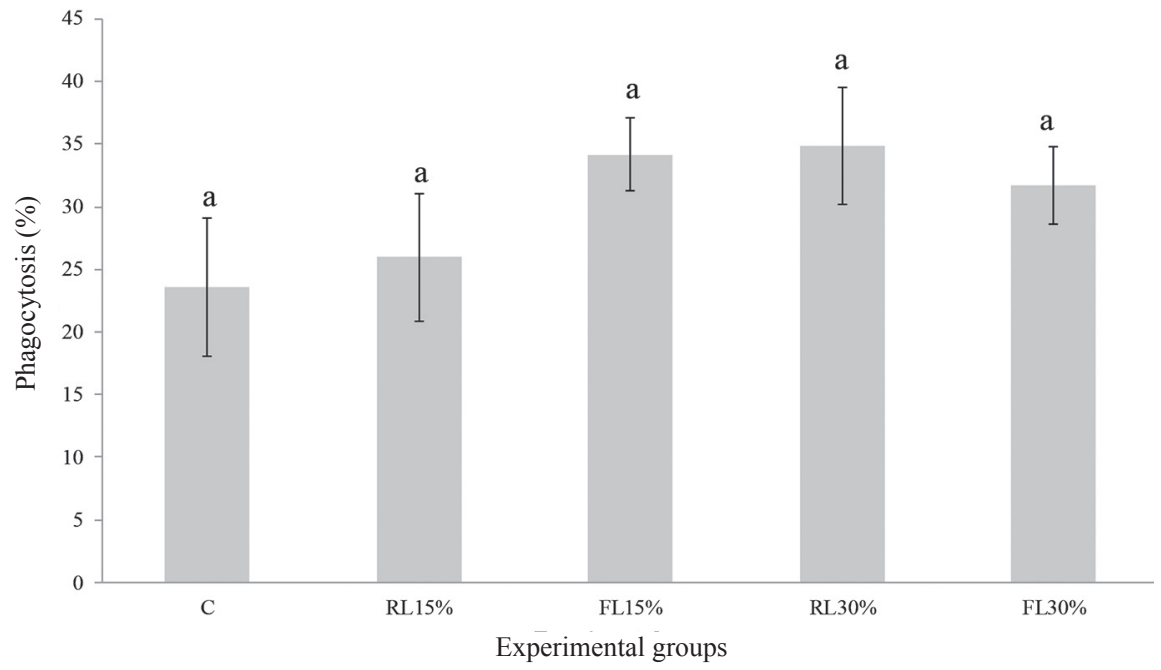

Figure 3. Phagocytic activity (mean $\pm \mathrm{SD}, \mathrm{n}=8$ ), after an 8 -week feeding test, of juvenile Atlantic salmon (Salmo salar) fed experimental diets formulated with 15\% and 30\% replacement of fish meal by either raw or fermented lupin meal

\section{Discussion}

L. plantarum has been widely researched in fermentation processes of plant meals. However, few investigations have been conducted with this species of bac- 
teria to bioprocess plant meals used as fish meal replacers in fish diets. In present study, lupin meal was fermented by L. plantarum 299v under controlled conditions of temperature and humidity. After $36 \mathrm{~h}$ of fermentation, CFU increased notably. Similar observation was made by Pranoto et al. (2013) who found that fermenting sorghum flour with L. plantarum increased CFU by 5 log.

It is well documented that during fermentation of $L$. plantarum several reactions occur modifying some properties of fermented substrate such as moisture content (color variation of bioprocessed meal) and production of different metabolic products (e.g. secondary metabolites) (Smit et al., 2005). Our results agree with Vo et al. (2015) who observed a color change produced by an increased dry matter of fermented sweet lupin (L. angustifolius). Fermentation can result in variation of components like fibre and ash content in plant based ingredients. These variations can result in significant changes in color of fermented meal (Wang et al., 2016 a). In present study, content of fibre and ash in the fermented lupin meal were lower than the content of the raw meal. Previous studies have demonstrated that certain probiotic strains secrete various enzymes that worked synergistically to degrade fibres during the fermentation process, decreasing crude fibre content (Soccol et al., 2017). In this study, SSF increased protein $(7.89 \%)$ and decreased nitrogen-free extract $(4.26 \%)$ content in fermented lupin meal. Similar results were reported by Chi and Cho (2016) who observed that protein content in soybean meal increased $6.42 \%, 0.95 \%$, $1.91 \%$ and $5.61 \%$, in respect to control, after fermentation with Bacillus amyloliquefaciens U304, L. acidophilus, L. plantarum, and S. cerevisiae CJ1697, respectively. This increment of protein and reduction of nitrogen-free extract in fermented lupin meal, could be explained by the microbial capacity to decompose soluble polysaccharides into organic acids and carbon dioxide gas, reducing the total amount of carbohydrates (and thus the content of nitrogen-free extract) and increasing the level of protein content in fermented plant meals (Dai et al., 2017). Furthermore, another study showed that fermentation of lupin significantly reduced the amount of anti-nutritional factors (ANFs) and improved amino acid profiles of the lupin (L. angustifolius) fermented by L. acidophilus, L. aporogenes, and L. kefiri, for $72 \mathrm{~h}$ (Vo et al., 2015). These authors suggested that a significant reduction of ANFs in plant meals increased the level and bioavailability of certain nutrients such as protein.

Several investigations have been conducted to study organic acid production during Lactobacillus fermentation, processing carbohydrates and protein substrates through several metabolic pathways (Cizeikiene et al., 2018; Ho et al., 2018; Liong and Shah, 2005). In present research, lactic, citric and acetic acids were measured in L. plantarum 299v fermented lupin meal. Production of lactic acid by Lactobacillus sp. is well documented (Fu and Mathews, 1999). A significant production of lactic acid has been reported when fermenting molasses enriched potato stillage by L. paracasei (Mladenovic et al., 2018). In our study, citric acid was detected in a lower level $\left(13 \mathrm{~g} \mathrm{~kg}^{-1}\right)$, compared to that recorded by lactic acid. Citric acid is a common metabolite and an intermediate in cellular metabolism of all aerobic organisms (Srisukchayakul et al., 2018) such as Lactobacillus. Microbial production of citric acid during SSF methods has been previously reported. Hang et al. (1987) 
reported that fermentation of kiwi fruit peel by Aspergillus niger NRRL 567, can result in the production of $100 \mathrm{~g}$ of citric acid per $\mathrm{kg}$ of fermented substrate. In our study, we measured the acetic acid $\left(14 \mathrm{~g} \mathrm{~kg}^{-1}\right)$ produced from fermented lupin. Acetic acid production by Lactobacillus bacteria, has been studied in some aspects (OudeElferink et al., 2001) such as production patterns, and anaerobic conversion. A study led by Li et al. (2016) measured production of acetic acid during fermentation of plant substrates when algal carcass was bioprocessed with L. delbrueckii.

Quality and quantity of ingredients significantly affect nutrient contents in diets. Therefore, an accurate diet formulation is essential when fish meal is replaced by plant meals (Al-Thobaiti et al., 2017). Diets evaluated in this study were formulated to contain a balanced nutritional profile (isonitrogenous and isolipidic) to satisfy minimum requirements of Atlantic salmon. There were not significant differences observed in proximate composition among experimental diets designed with either fish meal, raw or fermented lupin. A previous study replacing fish meal in Atlantic salmon diets, by dehulled lupin meal did not show significant differences in proximal composition of experimental diets (Bransden et al., 2001). Although no significant differences were detected among experimental diets for juvenile Atlantic salmon, a slight decrease of fibre and ash was recorded as raw or fermented lupin meal increased. A decreased fibre ratio (compared to that of control diet) was also observed in a solid-state fermented feed for sea cucumber (Wang et al., 2016 a). Other authors found that ash ratio decreased as inclusion level of fermented lupin (as fish meal replacer) increased, in barramundi diets (Vo et al., 2015). In present study, nitrogenfree extract increased as raw or fermented lupin increased, this fact may be explained by high carbohydrate content of lupin and by the organic acid produced during the metabolization of polysaccharides and carbohydrates (starch, free sugars and nonstarch polysaccharides) (Smith et al., 2007).

Whole body proximate composition was not affected by consumption of experimental diets replacing raw or fermented lupin meal. Similar results were reported by Moniruzzaman et al. (2017), who observed that whole body proximate composition of final fish did not show any significant differences $(\mathrm{P}>0.05)$ among experimental groups of juvenile rainbow trout (Oncorhynchus mykiss) fed different types of fermented protein concentrates as fish meal replacer.

In present study, we evaluated two levels (15\% and $30 \%)$ of either raw or fermented lupin meal with Lactobacillus plantarum $299 \mathrm{v}$ as fish meal replacer in diets for Atlantic salmon. Although growth performance (e.g. SGR) of juvenile Atlantic salmon showed certain differences among experimental groups, growth was low. This can be explained by small size of initial fish (averaging $3.53 \pm 0.05 \mathrm{~g}$ ) and by environmental conditions (of the season) causing a significant variability of water temperature $14^{\circ} \mathrm{C} \pm 1.5$ during all experimental period. No differences in weight gain were detected among groups fed fish meal-based diet (C) and groups fed diets supplemented with raw lupin meal (RL15\% and RL30\%). Similar results were found by Acar et al. (2018) who found that replacing fish meal by raw lupin (L. albus) meal at $15 \%$ and $30 \%$ in rainbow trout (O. mykiss) diets did not cause adverse effects regarding growth parameters. Furthermore, Saez et al. (2015) observed that fish meal replacement with raw dehulled lupin meal did not affect growth of Atlantic salmon. 
This study demonstrated that replacing fish meal by $15 \%$ of fermented lupin meal, significantly improved growth performance (final body weight, weight gain, FCR, SGR and PER) of juvenile Atlantic salmon, compared to that of $\mathrm{C}$ experimental group and even to that of $15 \%$ supplementation of raw lupin meal. Our results agree with Vo et al. (2015) who observed that replacing fish meal by $45 \%$ and $60 \%$ of fermented sweet lupin, Lupinus angustifolius, significantly increased the final weight of barramundi compared to that shown in control group. Other authors reported an improvement in growth performance of sea cucumbers fed fermented artificial diets compared to that of cucumbers fed unfermented diets (Wang et al., 2016 a). Juvenile Atlantic salmon significantly enhanced growth when fed diets formulated with $15 \%$ of fermented lupin. This benefit can be explained by presence of beneficial bacterial residues (Shiu et al., 2013) and by the improved nutritional value of fermented meal (Vo et al., 2015) replacing fish meal in experimental diets. Although we did not assess amino acids content of raw and fermented lupin meal in fish diets, previous studies have demonstrated the evidence that SSF plant meals improve amino acids profiles hence favoring growth of fish when incorporated in aquafeeds (Dai et al., 2017; Vo et al., 2015).

SSF processes of plant meals apart from providing an improved nutrient profile to fish diets, enrich them with a blend of OA (namely OAB) and at the same time, acidifying obtained pellets ( $\mathrm{Ng}$ and $\mathrm{Koh}, 2016)$. Our experimental diets containing fermented lupin meal in their formulation, also recorded a decreased $\mathrm{pH}$ value $(-0.29$ for the FL $15 \%$ and -0.54 for the FL30\% experimental diets) in relation to $\mathrm{pH}$ registered in control diet. The $\mathrm{pH}$ reduction is ascribed to microbial production of shortchain organic acids functioning as "acidifiers" (Luckstadt, 2008). Previous studies have demonstrated that OA contained in fish diets affects $\mathrm{pH}$ of pellets (Castillo et al., 2014). Acidic pH modifies gastrointestinal tract physiology and energy utilization, consequently increasing the availability of nutrients and reducing the $\mathrm{pH}$ in the digestive tract through $\mathrm{H}^{+}$deposition (Luckstadt, 2008; Pandey and Satoh, 2008; Ringo 1991). Hence, presence of an OAB in experimental diets, may favor juvenile Atlantic salmon growth as shown in present study, where fish fed diet formulated with $15 \%$ of lupin meal showed an improved growth compared to that shown in C, RL15\% and FL30\% experimental groups. It is well demonstrated that individual OA has the capacity to improve growth in different species. Lactic acid has demonstrated growth improvement capacity in different species (Gislason et al., 1996; Ringo et al., 1994). Numerous studies have demonstrated that citric acid can improve growth and feed utilization in various fish species (Khajepour and Hosseini, 2012; Baruah et al., 2007). Sugiura et al. (2006) reported that dietary acetic acid decreases stomach $\mathrm{pH}$ and slightly reduces that of gut, increasing nutrient utilization of rainbow trout. In this study, fish fed FL15\% resulted in a significantly $(\mathrm{P}<0.05)$ higher growth performance compared to that of FL30\%. This difference could have been caused by the total amount of organic acid blend (OAB) present in each diet: $26.80 \mathrm{~g} \mathrm{~kg}^{-1}$ (FL15\%) and $96.31 \mathrm{~g} \mathrm{~kg}^{-1}$ (FL30\%) (Table 4). OAB contained in fermented lupin produced a positive synergistic effect (Koh et al., 2016) on growth of juvenile Atlantic salmon when fish meal was replaced by the fermented lupin meal at $15 \%$ but not at $30 \%$. Positive effects of $\mathrm{OAB}$ enormously rely on quantity present in diet as reported by 
Katya et al. (2018) who observed that a higher OAB level presence in diet caused a null or detrimental effect in olive flounder, Paralichthys olivaceus.

Nutrient digestibility is an important indicator that reflects digestive physiology of fish. In this study, we evaluated ADC of dry matter, protein, lipid, ash, nitrogenfree extract and gross energy. ADC of nutrients in experimental juvenile Atlantic salmon were not compromised when fish meal was replaced by raw lupin meal (at $15 \%$ or $30 \%$ levels). Although earliest studies have demonstrated the negative influences in nutrient digestion of fish in response to dietary plant proteins, evidences also indicate that raw plant-based protein feeding had no adverse effects on apparent digestibility of nutrients in aquatic animals (Gatlin et al., 2007). Hansen et al. (2006) reported that Atlantic cod may be fed with untreated plant-based feeds up to $44 \%$ without any adverse impact to nutrient digestibility. A high inclusion of a mixture of raw materials (soybean, wheat gluten and corn gluten meal) was used in juveniles of turbot (Psetta maxima) diets without compromising digestibility and gut histology (Bonaldo et al., 2011).

Use of fermented plant meals has reported certain modifications in nutrient digestibility of fish (Vo et al., 2015). These effects significantly rely on supplementation level of fermented plant meal. In our study, although $30 \%$ replacement of fish meal by the fermented lupin meal did not improve ADC of nutrients compared to those shown in $\mathrm{C}$ diet, this supplementation level did not negatively compromise digestibility coefficients of nutrients. Neutral results were also found by Rahimnejad et al. (2019) who observed that SSF soybean did not negatively affect digestibility in Japanese seabass (Lateolabrax japonicus) fed diets replacing fish meal by fermented soybean meal by Pseudozyma aphidis ZR1. In contrast, other studies have found that $\mathrm{ADC}$ of nutrients has been improved when supplementing diets with plant meals treated by certain bio-thermal treatments. In our study, we used lupin meal previously submitted to a bio-thermal process. Compared to those values shown in $\mathrm{C}$ diet, $\mathrm{ADC}$ of protein and nitrogen-free extract was significantly higher in fish fed FL15\%. This fact may be explained by the evidence that a combined activity of different enzymes (amylase, cellulose, alginic acid enzyme and protease) enhances in aquatic animals consuming feeds supplemented with fermented meals at certain levels (Wang et al., 2016 b).

In our study, we observed an improvement in the ADC of protein in fish fed diets replacing fish meal by fermented lupin meal at $15 \%$. This benefit could be explained by an OAB present in experimental diet. Most of the OA have the function of stimulating secretion of gastric and digestive enzymes to improve protein digestion (Su et al., 2014). These physiological responses are exposed by previous results demonstrating an improvement in nutrient digestibility of fish fed diets containing organic acid blends (Koh et al., 2016; Ng et al., 2015). After our digestibility trial we observed an improvement in apparent digestibility coefficients of protein and nitrogen-free extract in fish fed diets containing $26.80 \mathrm{~g}$ of OAB per kg-1 $(\mathrm{FL} 15 \%)$ compared to fish fed a diet containing $96.31 \mathrm{~g}$ of the OAB per kg-1 (FL30\%) derived from a fermentation process. Koh et al. (2016) observed a higher digestibility of nutrients in red hybrid tilapia (Oreochromis sp.) fed diets containing $10 \mathrm{~g} \mathrm{~kg}^{-1}$ $\mathrm{OAB}$ than that recorded in $\mathrm{C}$ diet and even to that shown in fish fed diets containing 
$5 \mathrm{~g} \mathrm{~kg}^{-1}$. Another study demonstrated that nutrient digestibility was higher in white shrimp (Litopenaeus vannamei) fed diets containing $20 \mathrm{~g} \mathrm{~kg}^{-1}$ of OAB compared to those individuals fed 0, 10 and $40 \mathrm{~g}$ of OAB per kg-1 (Romano et al., 2015).

In this research we studied the immune response of fish fed diets formulated with raw and fermented lupin. Previous studies have reported results without negative effects on immunity of fish fed diets formulated with plant meals (Bransden et al., 2001). Fuentes-Quesada et al. (2018) reported no immunological inflammatory response when totoaba (Totoaba macdonaldi) was fed diets formulated with unprocessed soybean meal for eight weeks. Similarly, in our study, diets replacing fish meal by 15 or $30 \%$ of raw lupin meal, did not compromise immune status of fish. In contrast, our results also revealed that using SSF lupin at 15\%, increased lysozyme activity and respiratory burst of juvenile Atlantic salmon. Likewise, Rahimnejad et al. (2019) found that Japanese seabass fed diets replacing fish meal by fermented soybean meal by Bacillus pumillus improved lysozyme and complement activity. In our study we observed an improved immunity of juvenile Atlantic salmon, when SSF lupin (fermented with L. plantarum 299v), replaced fish meal at 15\%. A previous study, using L. plantarum P8 to ferment soybean meal supplemented in juvenile turbot (Scophthalmus maximus L.) diets reported a significant improved immune response (Wang et al., 2016 b) of this species. Using a mixture of SSF soybean meal and corn gluten meal with Bacillus subtilis as fish meal replacer at 30\% (FPC-A diet), Moniruzzaman et al. (2017) reported an improvement in superoxide dismutase, lysozyme and myeloperoxidase activities of rainbow trout (O. mykiss). This immune stimulation may be attributed to the presence of OA (produced by lactic acid bacteria during fermentation processes), in diets supplemented with SSF plant meals ( $\mathrm{Ng}$ and Koh, 2016). Immunomodulatory properties of OA in aquatic organisms have been previously demonstrated (Su et al., 2014; Abu-Elala and Ragaa, 2015; Liu et al., 2014). In our study, lysozyme activity of FL15\% experimental fish, was significantly higher and respiratory burst presented a higher tendency compared to those values shown in FL30\%. This difference could be attained to presence of OAB (26.80 g $\mathrm{kg}^{-1}$ and $96.31 \mathrm{~g} \mathrm{~kg}^{-1}$ ) in SSF lupin (15\% and 30\%, respectively). Immune response of fish, enormously relies on level of OAB present in diets. He et al. (2017) observed that an $\mathrm{OAB}$ (composed by $25 \%$ of citric acid and $16.7 \%$ of ascorbic acid) supplemented at $0.9 \mathrm{~g} \mathrm{~kg}^{-1}$ and $1.2 \mathrm{~g} \mathrm{~kg}^{-1}$, produced a significantly higher immune response in Pacific white shrimp (L. vannamei) compared to that shown in experimental groups fed supplemented diets with $0.0,0.3$ and $0.6 \mathrm{~g} \mathrm{~kg}^{-1}$ of the same OAB.

In conclusion, replacement of fish meal by raw and fermented lupin did not compromise growth, nutrient digestibility or immune status of juvenile Atlantic salmon. In our study, it was demonstrated that when supplementing fermented lupin meal at a certain level (15\%), growth performance, nutrient digestibility and immune response of juveniles of Atlantic salmon, was improved. While a 30\% replacement of fish meal by fermented lupin did not show improvements. These differences may be attributed to different levels of OAB (lactic, citric and acetic acids) derived from fermented lupin meal (with L. plantarum) supplemented in each diet. Use of fermented lupin meal may represent a promising alternative for replacing fish meal in aquafeeds. 


\section{Acknowledgements}

This study was funded by the project: "Concurso Interno de Investigación (internal research grant)" of Catholic University of Temuco. The authors would like to greatly appreciate the kind cooperation and technical assistance of Majorie Larson and Ingrid Hoppe for sample analysis, to Alex Oporto for experimental diets manufacturing and to students and technical personnel of De la Frontera University (UFRO) for SSF process assistance.

\section{References}

A b u - E 1 a 1 a N.M., R a g a a N.M. (2015). Eubiotic effect of a dietary acidifier (potassium diformate) in the health status of cultured Oreochromis niloticus. J. Adv. Res., 6: 621-629.

A c ar U., K e s b i c O.S., Y i l m a z S., K a r a b a y ir A. (2018). Growth performance, hematological and serum biochemical profiles in rainbow trout (Oncorhynchus mykiss) fed varying levels of lupin (Lupinus albus) meal. Aquac. Res., 49: 2579-2586.

A l- Th ob a it i A., A l-Gh a n im K., S u 1 i m an E.M., M a h b o o b S. (2017). Impact of replacing fish meal by a mixture of different plant protein sources on the growth performance of Nile tilapia (Oreochromis niloticus L.) diets. Braz. J. Biol., 78, http://dx.doi.org/10.1590/1519-6984.172230

AOAC (1995). Official Methods of Analysis of the Association of Analytical Chemists. 16th ed. Washington, DC.

B a r u a h K., S a hu N.P., P a 1 A.K., J a in K.K., D e bn a th D., M u kh e rj e e S.C. (2007). Dietary microbial phytase and citric acid synergistically enhances nutrient digestibility and growth performance of Labeo rohita (Hamilton) juveniles at sub-optimal protein level. Aquac. Res., 38: 109-120.

Bonaldo A., Parma L., Mandrioli L., Sirri R., Fontanillas R., Badiani A., Gatta P.P. (2011). Increasing dietary plant proteins affect growth performance and ammonia excretion but not digestibility and gut histology in turbot (Psetta maxima) juveniles. Aquaculture, 318: $101-108$.

B ransde n M.P., Carter C.G., N ow a k B.F. (2001). Effect of dietary protein source on growth, immune function, blood chemistry and disease resistance of Atlantic salmon (Salmo salar L.) parr. Anim. Sci., 73: 105-113.

Castillo S., Rosales M., Pohlenz C., Gatlin III D.M. (2014). Effects of organic acids on growth performance and digestive enzyme activities of juvenile red drum Sciaenops ocellatus. Aquaculture, 433: 6-12.

C h i C-H., C h o S-J. (2016). Improvement of bioactivity of soybean meal by solid-state fermentation with Bacillus amyloliquefaciens versus Lactobacillus spp. and Saccharomyces cerevisiae. LWTFood Sci. Tech., 68: 619-625.

Cizeikiene D., Juodeikiene G., Damasius J. (2018). Use of wheat straw biomass in production of L-lactic acid applying biocatalysts and combined lactic acid bacteria strains belonging to the genus Lactobacillus. Biocatal. Agri. Biotechnol., 15: 185-191.

$\mathrm{C}$ unh a S.C., F erre ir a I.M.P.L.V.O., F e rn and e s J.O., F ari a M.A., B e a tri z M., O 1 iv e i r a P.P., F e rre ir a M.A. (2001). Determination of lactic, acetic, succinic, and citric acids in table olives by HPLC/UV. J. Liq. Chromatogr. R. T., 24: 1029-1038.

D a i C., M a H., H e R., H u an g L., Z h u S., D in g Q., L u o L. (2017). Improvement of nutritional value and bioactivity of soybean meal by solid-state fermentation with Bacillus subtilis. LWT, 86: $1-7$.

F u W., M a the w s A.P. (1999). Lactic acid production from lactose by Lactobacillus plantarum: kinetic model and effects of pH, substrate and oxygen. Biochem. Eng. J., 3: 163-170.

Fuentes-Quesada J., Viana M.T., Rombenso A.N., Guerrero-Rentería Y., Nomura-Solís M., Gómez-Calle V., Lazo J.P., Mata-Sotres J.A. (2018). Enteritis induction by soybean meal in Toaba macdonaldi diets: Effects on growth performance, digestive capacity, immune response and distal intestine integrity. Aquaculture, 495: 78-89. 
F urukaw a A., Ts u kah a r a H. (1996). On the acid digestion method for the determination of chromic oxide as an index substance in the study of digestibility of fish feed. Bulletin Jpn. Soc. Sci. Fish., 32: 502-506.

Ga o X., Zhang M., Li X., Han Y., Wu F., Li u Y. (2018). The effects of feeding Lactobacillus pentosus on growth, immunity, and disease resistance in Haliotis discus hannai Ino. Fish Shellfish Immunol., 78: 42-51.

Gatl in III D.M., B arrow s F.T., B row n P., D a brow s k y K., G a y lord T.G., Hard y R.W., Wurtele, E. (2007). Expanding the utilization of sustainable plant products in aquafeeds: a review. Aquac. Res., 38: 551-579.

Gir i S.S., S u ku m a r a n V., O vi y a M. (2013). Potential probiotic Lactobacillus plantarum VSG3 improves the growth, immunity, and disease resistance of tropical freshwater fish, Labeo rohita. Fish Shellfish Immunol., 34: 660-666.

G is l a s o n G., O l s e n R.E., H in g e E. (1996). Comparative effects of dietary Na+-lactate on Arctic char, Salvelinus alpinus L., and Atlantic salmon, Salmo salar L. Aquac. Res., 27: 429-435.

G l e n c r o s s D.B., B o u j a r d T., K a u s h i k S.J. (2003). Influence of oligosaccharides on the digestibility of lupin meals when fed to rainbow trout, Oncorhynchus mykiss. Aquaculture, 219: 703-713.

Hang Y.D., Luh B.S., Wo od a m s E.E. (1987). Microbial production of citric acid by solid state fermentation of kiwifruit peel. J. Food Sci., 52: 226-227.

H a n s e n A-C., R o s e l und G., K a r ls e n O., O l s v i k P.A., H e m r e G-I. (2006). The inclusion of plant protein in cod diets, its effects on macronutrient digestibility, gut and liver histology and heat shock protein transcription. Aquac. Res., 37: 773-784.

He W., Rahimnejad S., Wang L., Song K., Lu K., Zhang C. (2017). Effects of organic acid and essential oils blend on growth, gut microbiota, immune response and disease resistance of Pacific white shrimp (Litopenaeus vannamei) against Vibrio parahaemolyticus. Fish Shellfish Immunol., 70: 164-173.

H o V.T.T., F 1 e e t G.H., Z h a o J. (2018). Unravelling the contribution of lactic acid bacteria and acetic acid bacteria to coca fermentation using inoculating organisms. Intl. J. Food Microbiol., 279: 43-56.

Johansen R., N e edham J.R., Colquhoun D.J., P op pe T.T., S m ith J. (2006). Guidelines for health and welfare monitoring of fish use in research. Laboratory Animals, 40: 323-340.

K a ty a K., P ark G., B har a dwaj A.S., B row dy C., Vazquez-A non M., B a i S.C. (2018). Organic acids blend as dietary antibiotic replacer in marine fish olive flounder, Paralichthys olivaceus. Aquac. Res., 49: 2861-2868.

K h a j e p o ur F., H o s s e in i S.A. (2012). Citric acid improves growth performance and phosphorous digestibility in Beluga (Huso huso) fed diets where soybean meal partly replaced fish meal. Anim. Feed Sci. Tech., 171: 68-73.

K o h C-B., R o m a n o N., Z a hr a h A.S., N g W-K (2016). Effects of dietary organic acid blend and oxytetracycline on the growth, nutrient utilization and total cultivable gut microbiota of the red hybrid tilapia, Oreochromis sp., and resistance to Streptococcus agalactiae. Aquac. Res., 47: 357-369.

Li C., Zhang G.F., M a o X., Wang J.Y., D u a n C.Y., Wang Z.J., Li u L.B. (2016). Growth and acid production of Lactobacillus delbrueckii spp. Bulgaricus ATCC 11842 in the fermentation of algal carcass. J. Dairy Sci., 99: 4243-4250.

Li ong M.T., Shah N.P. (2005). Production of organic acids from fermentation of mannitol, fructooligosaccharide and inulin by a cholesterol removing Lactobacillus acidophilus strain. J. Appl. Microbiol., 99: 783-793.

Li u W., Yang Y., Zhang J., G atlin D.M., Ring o E., Zhou Z. (2014). Effects of dietary microencapsulated sodium butyrate on growth, intestinal mucosal morphology, immune response, and adhesive bacteria in juvenile common carp (Cyprinus carpio) pre-fed with or without oxidized oil. Brit. J. Nutr., 112: 15-29.

Luckstadt C. (2008). The use of acidifiers in fish nutrition. CAB Rev. Persp. Agr. Vet. Sci. Nutr. Nat. Res., 3: 1-8.

Mladenovic D., Pejin J., Kocic-Tanackov S., Radovanovic Z., Djukic-Vukovic A., Mojovic L. (2018). Lactic acid production on molasses enriched potato stillage by Lactobacillus paracasei immobilized on fish agro-industrial waste supports. Ind. Crop. Prod., 124: $142-148$.

Moniruzzaman M., B a e J.H., Won S.H., Cho S.J., Chang K.H., B a i S.C. (2017). Evalu- 
ation of solid-state fermented protein concentrates as a fish meal replacer in the diets of juvenile rainbow trout Oncorhynchus mykiss. Aquac. Nutr., 24: 1198-1212.

$\mathrm{Ng} \mathrm{W-K.,} \mathrm{K} \mathrm{o} \mathrm{h} \mathrm{C.B.} \mathrm{(2016).} \mathrm{The} \mathrm{utilization} \mathrm{and} \mathrm{mode} \mathrm{of} \mathrm{action} \mathrm{of} \mathrm{organic} \mathrm{acids} \mathrm{in} \mathrm{the} \mathrm{feeds} \mathrm{of} \mathrm{cultured}$ aquatic animals. Rev. Aquacult., 9: 342-368.

N g W-K., K o h C-B., Te o h C-T., R o m a n o N. (2015). Farm-raised shrimp, Penaeus monodon, fed commercial feeds with added organic acids showed enhanced nutrient utilization, immune response and resistance to Vibrio harveyi challenge. Aquaculture, 449: 69-77.

Oude-Elferink S.J.W.H., Kroonem an J., Gotts chal J.C., S poelstra S.F., Faber F., $\mathrm{Dr}$ i e hu is F. (2001). Aerobic conversion of lactic acid to acetic acid and 1,2-propaneidol by Lactobacillus buchneri. Appl. Environ. Microb., 67: 125-132.

P a n d e y A. (2003). Solid-state fermentation. Biochem. Eng. J., 13: 8-84.

P a n dey A., S a t oh S. (2008). Effects of organic acids on growth and phosphorous utilization in rainbow trout Oncorhynchus mykiss. Fish. Sci., 74: 867-874.

Panigrahi A., Kiron V., Kobayashi T., Puangkaew J., S atoh S., Sugita H. (2004). Immune responses in rainbow trout Oncorhynchus mykiss induced by a potential probiotic bacteria Lactobacillus rhamnosus JCM 1136. Vet. Immunol. Immunopatol., 102: 379-388.

P a r ry R.M., Chand a n R.C., S h a h a n i K.M. (1965). A rapid and sensitive assay of muramidase. P. Soc. Exp. Biol., 119: 301-306.

Pranoto Y., Anggrahini S., Efendi Z. (2013). Effect of natural and Lactobacillus plantarum fermentation on in-vitro protein and starch digestibilities of sorghum flour. Food Biosci., 2: 46-52.

Rah imnej a d S., Lu K., Wang L., S ong K., Ma i K., D a v is D.A., Zhang C. (2019). Replacement of fish meal with Bacillus pumillus SE5 and Pseudozyma aphidis ZR1 fermented soybean meal in diets for Japanese seabass (Lateolabrax japonicus). Fish Shellfish Immunol., 84: 987-997.

R a y M. (2001). Effect of fermentation on the nutritive value of sesame seed meal in the diets for rohu, Labeo rohita (Hamilton), fingerlings. Aquac. Nutr., 54: 229-236.

R in g o E. (1991). Effects of dietary lactate and propionate on growth and ingesta in Arctic charr, Salvelinus alpinus (L.). Aquaculture, 96: 321-333.

R in g o E., O 1 s e n R.E., C a s t e 11 J.D. (1994). Effect of dietary lactate on growth and chemical composition of Arctic charr Salvelinus alpinus. J. World Aquacult. Soc., 25: 483-486.

R o m a n o N., K o h C-B., N g W-K. (2015). Dietary microencapsulated organic acids blend enhances growth, phosphorous utilization, immune response, hepatopancreatic integrity and resistance against Vibrio harveyi in white shrimp, Litopenaeus vannamei. Aquaculture, 435: 228-236.

Saez P., B orquez A., Da ntagnan P., Hernández A. (2015). Effects of dehulling, steamcooking and microwave-irradiation in digestive value of white lupin (Lupinus albus) seed meal for rainbow trout (Oncorhynchus mykiss) and Atlantic salmon (Salmo salar). Arch. Anim. Nutri., 69: $143-157$.

S a ka i M., K ob a y s hi M., Kaw a u chi H. (1996). In vitro activation of fish phagocytosis cells by $\mathrm{GH}$, prolactin and somatolactin. J. Endocrinol., 151: 113-118.

S a lin i M.J., Adams L.R. (2014). Growth performance, nutrient utilization and digestibility by Atlantic salmon (Salmo salar) fed Tasmanian grown white (Lupinus albus) and narrow-leafed (L. angustifolius) lupins. Aquaculture, 426-427: 296-303.

S a r k e r M.S.A., S a t o h S., K a m a t a K., Ha ga Y., Y a m a m o to Y. (2011). Partial replacement of fish meal with plant protein sources using organic acids to practical diets for juvenile yellowtail, Seriola quinqueradiata. Aquacult. Nutr., 18: 81-89.

S h a r a w y Z., G o d a A. M.A.S., H a s s a a n M.S. (2016). Partial or total replacement of fish meal by solid state fermented soybean meal with Saccharomyces cerevisiae in diets for Indian prawn shrimp, Fenneropenaeus indicus, postlarvae. Anim. Feed Sci. Tech., 212: 90-99.

Shi u Y-L., H s i e h S-L., Gu e i W-C., Ts a i Y-T., Ch i u C-H., Li u C-H. (2013). Using Bacillus subtilis E20-fermented soybean meal as replacement for fish meal in the diet of orange-spotted grouper (Epinephelus coioides, Hamilton). Aquacult. Res., 46: 1403-1416.

$\mathrm{S} \mathrm{m}$ it G., S m it B.A., En g e ls W.J. (2005). Flavor formation by lactic acid bacteria and biochemical flavor profiling of cheese products. FEMS of Microbiol. Rev., 29: 591-610.

S m ith D.M., Tabret t S.J., G 1 e n cros s B.D., Irvin S.J., B a r c l a y M.C. (2007). Digestibility of lupin kernel meals in feeds for the black tiger shrimp, Penaeus monodon. Aquaculture, 264: 353-362. 
Soccol C.R., Scopel-Ferreira da Costa E., Junior-Letti J.A., Karp S.G., Woiciechowski A.L., Porto de Souza-Vandenberghe L. (2017). Recent developments and innovations in solid state fermentation. Biotech. Res. Innov., 1: 52-71.

Srisukchayakul P., Charala mpopoulos D., Karatzas K. (2018). Study on the effect of citric acid adaptation toward the subsequent survival of Lactobacillus plantarum NCIMB 8826 in low $\mathrm{pH}$ fruit juices during refrigerated storage. Food Res. Intl., 111: 198-204.

Su X., Li X., Leng X., Tan C., Li u B., Chai X., Guo T. (2014). The improvement of growth, digestive enzyme activity and disease resistance of white shrimp by the dietary citric acid. Aquacult. Intl., 22: 1823-1835.

S u gi ura S.H., R o y P.K., F erraris R.P. (2006). Dietary acidification enhances phosphorous digestibility but decreases $\mathrm{H}^{+} / \mathrm{K}^{+}$-ATPase expression in rainbow trout. J. Exp. Biol., 209: 3719-3728.

S un H., Tang J-W., Ya o X-H., Wu Y-F., Wang X., Li u Y., L o u B. (2015). Partial substitution of fish meal with fermented cottonseed meal in juvenile black sea bream (Acanthopagrus schlegelii) diets. Aquaculture, 446: 30-36.

Tabrett S., B lyth D., B ourne N., G len cross B. (2012). Digestibility of Lupinus albus lupin meals in barramundi (Lates calcarifer). Aquaculture, 364-365: 1-5.

Ta c o n A.G.J., M e t i a n M. (2015). Feed matters: satisfying the feed demand of aquaculture. Reviews in Fish. Sci. Aquacult., 23: 1-10.

Vand en berghe L.P.S., Karp S.G., d e Oliveira P.Z., d e Carvalho J.C., Rodrigues C., S o c c ol C.R. (2018). Chapter 18 - Solid-state fermentation for the production of organic acids. In: Current Developments in Biotechnology and Bioengineering. Current Advances in Solid-State Fermentation, Pandey A., Larroche C., Soccol C.R. (eds). Elsevier, Langford Lane, Kidlington, UK, pp. 415-434.

Van - D o a n H., D o o lg ind a c h b a p or n S., S u k s ri A. (2014). Effects of low molecular weight agar and Lactobacillus plantarum on growth performance, immunity, and disease resistance of basa fish (Pangasius bocourti, Sauvage 1880). Fish Shellfish Immunol., 41: 340-345.

Vi e $1 \mathrm{~m}$ a J., L a 11 S.P. (2006). Dietary formic acid enhanced apparent digestibility of minerals in rainbow trout, Oncorhynchus mykiss (Walbaum). Aquacult. Nutr., 3: 265-268.

Vo B.V., B u i D.P., N g u y e n H.Q., F ot e d a r R. (2015). Optimized fermented lupin (Lupinus angustifolius) inclusion in juvenile barramundi (Lates calcarifer) diets. Aquaculture, 444: 62-69.

Wang J.-H., G u o H., Z h ang T-R., Wang H., L i u B-N., X i a o S. (2016 a). Growth performance and digestion improvement of juvenile sea cucumber Apostichopus japonicus fed by solid-state fermentation diet. Aquacult. Nutr., 23: 1312-1318.

Wang L., Z h o u H., He R., X u W., M a i K., He G. (2016 b). Effect of soybean meal fermentation by Lactobacillus plantarum $\mathrm{P} 8$ on growth, immune responses, and intestinal morphology in juvenile turbot (Scophthalmus maximus L.). Aquaculture, 464: 87-94.

X i a Y., Lu M., Chen G., C a o J., G a o F., Wang M., Y i M. (2018). Effects of dietary Lactobacillus rhamnosus JMC1136 and Lactococcus lactis subs. Lactis JCM5805 on the growth, intestinal microbiota, morphology, immune response and disease resistance of juvenile Nile tilapia, Oreochromis niloticus. Fish Shellfish Immun., 76: 368-379.

Y in G., J e n e y G., R a c z T., P a o X., J e n e y Z. (2006). Effect of two Chinese herbs (Astragalus radix and Scutellaria radix) on non-specific immune response of tilapia, Oreochromis niloticus. Aquaculture, 253: 39-47.

Yu L., Zha i Q., Zhu J., Zhang C., Li T., Chen W. (2017). Dietary Lactobacillus plantarum supplementation enhances growth performance and alleviates aluminum toxicity in tilapia. Ecotox. Environ. Safe., 143: 307-314.

Zhang C., Rahimnejad S., Wang Y., Lu K., S ong K., Wang L., Mai K. (2018). Substituting fish meal with soybean meal in diets for Japanese seabass (Lateolabrax japonicus): Effects on growth, digestive enzymes activity, gut histology, and expression of gut inflammatory and transporter genes. Aquaculture, 483: 173-182.

Zhang T.S., Shi Y., Zhang S.L., Shang W., G a o X.Q., Wang H.K. (2014). Whole soybean as probiotic lactic acid bacteria carrier food in solid-state fermentation. Food Control, 41: 1-6. 